\title{
Front Matter: Volume 10837
}

, "Front Matter: Volume 10837," Proc. SPIE 10837, 9th International Symposium on Advanced Optical Manufacturing and Testing Technologies: Large Mirrors and Telescopes, 1083701 (11 January 2019); doi: $10.1117 / 12.2523530$ and Testing Technologies (AOMATT2018), 2018, Chengdu, China 


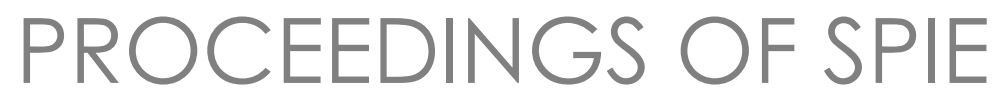

\title{
9th International Symposium on Advanced Optical Manufacturing and Testing Technologies
}

\section{Large Mirrors and Telescopes}

\author{
Xiaoliang Ma \\ Bin Fan \\ Yongjian Wan \\ Adrian Russell \\ Xiangang Luo \\ Editors
}

\section{6-29 June 2018 \\ Chengdu, China}

Organized by

Institute of Optics and Electronics, Chinese Academy of Sciences (China)

Sponsored by

COS-The Chinese Optical Society (China)

IOE-Institute of Optics and Electronics, Chinese Academy of Sciences (China)

Published by

SPIE 
The papers in this volume were part of the technical conference cited on the cover and title page. Papers were selected and subject to review by the editors and conference program committee. Some conference presentations may not be available for publication. Additional papers and presentation recordings may be available online in the SPIE Digital Library at SPIEDigitalLibrary.org.

The papers reflect the work and thoughts of the authors and are published herein as submitted. The publisher is not responsible for the validity of the information or for any outcomes resulting from reliance thereon.

Please use the following format to cite material from these proceedings:

Author(s), "Title of Paper," in 9th International Symposium on Advanced Optical Manufacturing and Testing Technologies: Large Mirrors and Telescopes, edited by Xiaoliang Ma, Bin Fan, Yongjian Wan, Adrian Russell, Xiangang Luo, Proceedings of SPIE Vol. 10837 (SPIE, Bellingham, WA, 2019) Seven-digit Article CID Number.

ISSN: 0277-786X

ISSN: 1996-756X (electronic)

ISBN: 9781510623163

ISBN: 9781510623170 (electronic)

Published by

SPIE

P.O. Box 10, Bellingham, Washington 98227-0010 USA

Telephone +1 3606763290 (Pacific Time) · Fax +1 3606471445

SPIE.org

Copyright @ 2019, Society of Photo-Optical Instrumentation Engineers.

Copying of material in this book for internal or personal use, or for the internal or personal use of specific clients, beyond the fair use provisions granted by the U.S. Copyright Law is authorized by SPIE subject to payment of copying fees. The Transactional Reporting Service base fee for this volume is $\$ 18.00$ per article (or portion thereof), which should be paid directly to the Copyright Clearance Center (CCC), 222 Rosewood Drive, Danvers, MA 01923. Payment may also be made electronically through CCC Online at copyright.com. Other copying for republication, resale, advertising or promotion, or any form of systematic or multiple reproduction of any material in this book is prohibited except with permission in writing from the publisher. The CCC fee code is 0277$786 \mathrm{X} / 19 / \$ 18.00$.

Printed in the United States of America.

Publication of record for individual papers is online in the SPIE Digital Library.

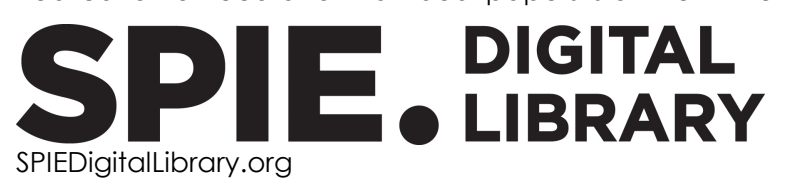

Paper Numbering: Proceedings of SPIE follow an e-First publication model. A unique citation identifier (CID) number is assigned to each article at the time of publication. Utilization of CIDs allows articles to be fully citable as soon as they are published online, and connects the same identifier to all online and print versions of the publication. SPIE uses a seven-digit CID article numbering system structured as follows:

- The first five digits correspond to the SPIE volume number.

- The last two digits indicate publication order within the volume using a Base 36 numbering system employing both numerals and letters. These two-number sets start with 00, 01, 02, 03, 04, 05, 06, 07, 08, 09, OA, OB ... 0Z, followed by 10-1Z, 20-2Z, etc. The CID Number appears on each page of the manuscript. 


\title{
Contents
}

\author{
vii Authors \\ ix Symposium Committees \\ Xi AOMATT 2018 Sponsors
}

LARGE MIRRORS AND TELESCOPES

1083702 A fiber bundle probe based on stacking-capillary method for LAMOST fiber positioning [10837-1]

1083703 Supporting structure design between primary and secondary mirrors in a long focal length space optical remote sensor [10837-4]

1083704 Mechanical design of zoom optical system for deep space exploration [10837-5]

1083705 Optical design of long transmission type ultraviolet detection system [10837-6]

1083706 On-orbit pointing adjusting mechanism of full-disc vector magnetograph (FMG) [10837-7]

1083707 Study on the effect of laser irradiation on high-order aberrations of deformable mirror by FEM [10837-9]

1083708 The basic research on phase-diversity phase retrieval in testing the large-aperture telescope [10837-11]

$1083709 \quad$ Mirrors fabricated with CFRP composites by replication technology [10837-13]

10837 OA Design of SiC mirror subsystem of a space-based astronomy telescope [10837-14]

10837 OB Design and test of a flexure mount for lightweight mirror [10837-15]

10837 OC Review on the new technologies to improve the resolution of spatial optical remote sensor [10837-16]

10837 OD Research on methods of enlarging field of view of the synthetic aperture lidar [10837-17]

10837 OE A prime focus corrector design for liquid mirror telescope [10837-18] 
10837 OF Influence of ply misalignment on form error in the manufacturing of CFRP mirrors with different layup sequences [10837-19]

10837 OG Design of pupil off-axis space telescope with freeform surfaces based on the nodal aberration theory [10837-21]

$10837 \mathrm{OH} \quad$ Design of integrated dual band microscope based on image consistency [10837-22]

10837 Ol Fabricating of $\mathbf{\Phi 4 m ~ C I O M P - S i C ~ m i r r o r ~ b l a n k ~ [ 1 0 8 3 7 - 2 3 ] ~}$

10837 oJ Curing shrinkage stress and deformation analysis of adhesive bonding large aperture mirror [10837-25]

10837 OK Optical design of diffractive telescope system based on off-axis three mirror [10837-26]

$10837 \mathrm{OL} \quad$ Analysis and correction about measurement error of edge sensor caused by guide flexure applied in the support system assembly of Thirty Meter Telescope [10837-27]

10837 OM Topology optimization design of cradle of GSSMP [10837-31]

10837 ON Normalized point source sensitivity analysis for GSSM of TMT [10837-32]

$1083700 \quad$ Mirror seeing and its evaluation [10837-33]

10837 OP Analysis of correlation algorithms for Shack-Hartmann wavefront sensors [10837-34]

10837 OQ Preliminary design of moment correction system for large optical components [10837-35]

10837 OR Telescope images segmentation with OTSU method [10837-36]

10837 OS Thirty Meter Telescope tertiary mirror system prototype cell assembly analysis [10837-38]

10837 OT The optical design and stray light suppression of compact large aperture space telescope [10837-39]

10837 oU Wide-field and large aperture optical system design for ground-based photoelectric detection [10837-40]

10837 OV Manufacturing and testing of surface modified silicon carbide aspheric mirror [10837-41]

10837 oW Optical freeform surface generation by modal Zernike method with optimum sampling data type to realize accurate wavefront matching [10837-45]

10837 OX High reflecting film deposition of all-CFRP mirror [10837-46]

10837 OY The study of free form optical elements corrected aberrations of optical system [10837-50] 
$10837 \mathrm{OZ}$ Design of off-axis three-mirror freeform optical system with wide field of view [10837-58]

1083710 Optical design of off-axis three-mirror system with long focal length and wide field of view [10837-74]

1083711 Study on edge-trimming experiment of a reflective mirror [10837-87]

1083712 Study on the fabrication of a high precision aluminum alloy cylindrical mirror with combined process [10837-117]

1083713 Design of the front window of full-disc vector magnetograph [10837-123]

1083714 Effect and control of central deviation on the imaging quality of high magnification continuous zoom TV [10837-127]

1083715 Highly compact optical design of an off-axis three-mirror system with freeform surfaces [10837-132]

1083716 Research on stitching metrology of large aperture continuous spiral phase plate [10837-134]

1083717 Research on combined surface modification of single crystal silicon cylindrical mirror [10837-135]

1083718 A study on analysis and control for eccentric error of common path optical system [10837-138]

1083719 Study on the destructive measurement of subsurface damage for fused silica mirror [10837-143]

10837 1A Research on computer-aided alignment for an afocal off-axis optical system [10837-343]

10837 1B Study of ultra-precision polishing of electroless nickel molding dies [10837-501]

10837 1C Performance comparison between two kinds of variable curvature mirrors: mathematical analysis, prototype design, experimental demonstration, and application potentials in realizing non-moving element optical zooming [10837-543] 
Proc. of SPIE Vol. 10837 1083701-6

Downloaded From: https://www.spiedigitallibrary.org/conference-proceedings-of-spie on 26 Apr 2023 Terms of Use: https://www.spiedigitallibrary.org/terms-of-use 
Rui, Congshan, OF

Shan, Qiusha, OU

She, Wenji, oU

Shi, Feng, 17

Shi, Haodong, OG

Shi, Jinfeng, 06

Shi, Kai, 14

Song, $\mathrm{Ci}, 17$

Song, Yang, 06

Sun, Jian, OJ

Sun, Li-jun, OJ

Sun, Yi, 04

Sun, Zhenguo, 06

Tang, Zhenghong, OE

Tian, Chunlin, $\mathrm{OZ}$

Tian, Ye, 17

Tong, Yi, 19

Wang, Bin, 08

Wang, Bo, 1B

Wang, Chao, OG

Wang, Huijun, 11

Wang, Jianli, 08

Wang, Lei, 05, 0Z, 10

Wang, Lingjie, $0 G$

Wang, Meng, 02

Wang, Wei, 06

Wang, Xingfeng, 13

Wang, Xun, OP

Wang, Yonggang, 11

Wang, Yongjie, 09, 0X

Wang, Yuming, 05, 0Z, 10

Wang, Zhangli, 14

Wang, Zhangli, 18

Wang, Zhongqiang, 14

Wu, Jun-qiang, OJ

Wu, Mengyuan, 03

Wu, Xiaoge, 09, 0X

Wu, Yangong, 1B

Xia, Siyu, 06

Xian, Hao, OR

Xiang, Meng, OC, OD

Xie, Xiaopeng, $1 \mathrm{C}$

Xie, Yongjie, OX

Xiong, Zhaojun, OP

$X \cup$, Bing, $O P$

$X \cup$, Jun, OT

$\mathrm{Xu}$, Liang, 09, OX, 1C

Xue, Bin, OD

Xue, Jiadai, 1B

Yan, Hao, 16

Yan, Peipei, OU

Yan, Xingtao, OD

Yang, Can, 12

Yang, Fei, OL, OM, ON, OO, OQ, OS

Yang, Haicheng, 18

Yang, Jianfeng, 04, 13

Yang, Jing, 02

Yang, Kangjian, OP

Yang, Min, 02

Yang, Ping, $O P$
Yang, Wenqiang, 04

Yang, Yanji, 1B

Yang, Yifei, OS

Yang, Yongqing, $\mathrm{OU}$

Ye, Jing, 03

Yin, Huan, OT

Yin, Limei, 08

Yu, Jianhai, 11

Yu, Xin, OP

Yuan, Libo, 02

Yue, Peng-yuan, 1A

Zeng, Chunmei, OF

Zhang, Ang, OR

Zhang, Chao, 1A

Zhang, Ge, OI

Zhang, Hao-su, OB

Zhang, Jiaming, 02

Zhang, Jing, $0 \mathrm{~N}, 0 \mathrm{O}$

Zhang, Jingxu, OL, OQ, OS

Zhang, Jiyou, 11

Zhang, Wanli, 17

Zhang, Xiangming, 14

Zhang, Xin, OT

Zhang, Yan, 18

Zhang, Yao-ping, 07

Zhang, Yunlong, 14

Zhang, Zhi-fei, IA

Zhao, Hongchao, OL, OM, ON, OO, OQ, OS

Zhao, Hongjun, 18

Zhao, Hui, 1C

Zhao, Qiang, 0J

Zhao, Wang, OP

Zhao, Xi-ting, lA

Zhao, Yiyi, OC, OD

Zheng, Lixin, $\mathrm{OE}$

Zhou, Hong, 07

Zhou, Xiaobin, 18

Zhou, Yuming, 11

Zhu, Jun, OT

Zhu, Rong, OW

Zhu, Yang, OT

Zhu, Yongwei, 19

Zou, Gang-yi, OA, OY, 1C

Zuo, Xiaozhou, 18

viii

Proc. of SPIE Vol. 10837 1083701-8 


\title{
Symposium Committees
}

\author{
Symposium General Chairs
}

Bingkun Zhou, Tsinghua University (China)

Guangcan Guo, University of Science and Technology of China (China)

Liwei Zhou, Beijing Institute of Technology (China)

Qihuang Gong, Peking University (China)

Henri Lezec, National Institute of Standards and Technology (United States)

Minghui Hong, National University of Singapore (Singapore)

Yuwen Qin, National Natural Science Foundation of China (China)

Yudong Zhang, Chengdu Branch of Chinese Academy of Sciences (China)

Enhai Liu, Institute of Optics and Electronics (China)

International Advisory Committee

Wenhan Jiang, Institute of Optics and Electronics (China)

Yuen-Ron Shen, University of California, Berkeley (United States)

Myung K. Cho, National Optical Astronomy Observatory (United States)

Organizing Committee

Jinghua Cao, CAS Bureau of International Cooperation (China)

Yadong Jiang, University of Electronic Science and Technology of China (China)

Li Yang, Institute of Optics and Electronics (China)

Program Committee

Hu Yang, Institute of Optics and Electronics, CAS (China)

Xiaodi Tan, Beijing Institute of Technology (China)

Ting Xu, Nanjing University (China)

Qiao Xu, China Academy of Engineering Physics (China)

Xuanming Duan, Chongqing Institute of Green and Intelligent

Technology (China)

Xue Feng, Tsinghua University (China)

Junsheng Yu, University of Electronic Science and Technology of China (China)

Xinbin Cheng, Tongji University (China) 
Zheyu Fang, Peking University (China)

Rui Zhou, Xiamen University (China)

Changtao Wang, Institute of Optics and Electronics (China)

\section{Conference Chairs}

Wenhan Jiang, Institute of Optics and Electronics (China)

Myung K. Cho, National Optical Astronomy Observatory (United States)

Hao Xian, Institute of Optics and Electronics (China)

Bin Fan, Institute of Optics and Electronics (China) 


\title{
AOMATT 2018 SPONSORS
}

\author{
Organized by \\ Institute of Optics and Electronics, Chinese Academy of Sciences (China) \\ Sponsored by \\ COS-The Chinese Optical Society (China) \\ IOE-Institute of Optics and Electronics, Chinese Academy of Sciences \\ (China) \\ Technical Co-sponsor \\ SPIE \\ Supported by \\ Ministry of Science and Technology of China (China) \\ Chinese Academy of Sciences (China) \\ National Natural Science Foundation of China (China)
}


Proc. of SPIE Vol. 10837 1083701-12 Downloaded From: https://www.spiedigitallibrary.org/conference-proceedings-of-spie on 26 Apr 2023
Terms of Use: https://www.spiedigitallibrary.org/terms-of-use 